\title{
La angustia como modo propio de ser sí mismo*
}

\section{The distress as an own way to be oneself}

\author{
Prof. Ana A. Moyano**
}

\begin{abstract}
Resumen: Este artículo aborda el tema de la angustia desde una revisión escueta de los intentos infrecuentes de tematizarla a lo largo de la historia de la filosofía. Comenzando por la antigua teoría humoral y pasando por los medievales, Kierkegaard y Freud hasta Heidegger, atravesando la teología, la psicología y la filosofía y poniendo de relieve algunas características de la angustia siempre presentes como la ambigüedad, el retraerse y la fuga. Se comprenderá que la angustia es el modo propio de ser sí mismo, aunque usualmente rechazado y malinterpretado.
\end{abstract}

Palabras clave: Angustia - Melancolía - Retraerse - Fuga - Ambigüedad

\begin{abstract}
This article approaches the topic of the distress across a succinct review of the infrequent attempts of treating it along philosophy history. Starting on humoral theory of the ancient Greeks, then the medieval, Kierkegaard and Freud up to Heidegger, crossing theology, psychology and philosophy and emphasizing some of the distress characteristics always present such as the ambiguity, the re-bring to oneself and the escape. It will be understand that the distress is the own way of being oneself, though usually rejected and misunderstood.
\end{abstract}

Key words: Distress-Melancholy- Re bring to oneself-Escape-Ambiguity

* Originalmente una monografía, este artículo se gesta en el contexto de la materia Historia de la Filosofía Contemporánea en el año 2007 en la Facultad de Filosofía y Letras de la Universidad Nacional de Cuyo (Mendoza, Argentina), contando con la invaluable guía de la Profesora Yolanda Russo. ** Argentina. Profesora de Filosofía por la Facultad de Filosofía y Letras de la Universidad Nacional de Cuyo (Mendoza, Argentina). Estudiante de intercambio en la Universidad Católica Silva Henríquez durante el segundo semestre de 2009 y primero de 2010. Contacto: anamoyano12@gmail.com 
Un vistazo a lo largo del pensamiento occidental nos muestra repetidas veces la presencia de la angustia como una inquietud para el pensar. Resaltar este hecho es importante en cuanto que, lejos de ser un tema ya agotado, se trata de una reaparición de lo impostergable, de algo esencial y original.

En las distintas épocas, la experiencia de la angustia adoptó diferentes términos (en diferentes idiomas): acedia y tristeza en el Medioevo, melancolía en la Modernidad, angustia desde la Contemporaneidad. Sin embargo, lo que nos ocupa, de aquí en más, no es un estudio morfológico del término sino, por el contrario, el movimiento intrínseco en la comprensión de la angustia a través de distintas épocas y autores.

En la antigua teoría humoral', la melancolía fue considerada como una enfermedad producida por el humor negro en el tipo humano contemplativo, es decir, en hombres propensos al recogimiento interior y a la contemplación. Además, esta teoría sostenía que el hombre melancólico padecía de un silbido en la oreja izquierda y, por este motivo, las más antiguas representaciones del melancólico muestran a un hombre cubriéndose su oreja con la mano.

En la época medieval la figura del hombre melancólico fue asociada al hombre religioso y la representación de la mano sobre la oreja izquierda se interpretó como un hombre que apoyaba la cabeza en la mano debido al sueño que le provocaba su pereza. Es entonces cuando la melancolía comienza a considerarse un pecado. Casiano

1 El humorismo es la doctrina médica sostenida por Hipócrates (Cos, 460 a. C.-Tesalia, 370 a. C.) y la escuela de Cos, según la cual las enfermedades resultaban de la alteración de los cuatro humores cardinales en calidad o en cantidad: sangre, flema, bilis amarilla o bilis negra. Además hay cuatro tipos de temperamentos, considerados como emanación del alma por la interrelación de los diferentes humores del cuerpo: sanguíneos, las personas con un humor muy variable; melancólicos, personas tristes y soñadoras; coléricos, personas cuyo humor se caracterizaba por una voluntad fuerte y unos sentimientos impulsivos, en las que predominaba la bilis amarilla y blanca, y flemáticos, personas lentas y apáticas, a veces con mucha sangre fría, en las cuales la flema era el componente predominante de los humores del cuerpo. 
(entre 360 y 365-ca. 435) y San Gregorio Magno (ca. 540-604) hacen una enumeración de las hijas de la acedia ${ }^{2}$, todas ligadas a un mismo "demonio meridiano" 3 que asolaba a los hombres religiosos recluidos en abadías y los amenazaba con el más letal de los vicios: la muerte del alma.

Sin embargo, otras perspectivas durante la Patrística distinguen dos tipos de 'tristitia': una 'tristitia mortifera', experimentada por los hombres como la tristeza que surge del desesperado hundirse en el abismo que se abre entre el deseo y su inasible objeto; pero también una 'tristitia salutifera', la virtud operadora de la salvación en la cual la privación se convierte en posesión. En esta última, el hombre contemplativo se descubre privado de su objeto inalcanzable (Dios) y con un deseo permanente por alcanzar esa meta. Ahora bien, para que una meta exista, debe ser planteada como tal $y$, si bien en este caso se trata de una meta inalcanzable, es necesario hacer notar que toda privación supone en algún punto posesión, ya que sólo se puede estar privado de aquello que antes ya se ha poseído, en mayor o menor medida.

Durante la Escolástica, Santo Tomás (1225-1274 d.C.) sostuvo que una de las características fundamentales de la angustia es el 'recessus $^{\prime 4}$, el retraerse del hombre ante Dios por la tristeza que le adviene al conocer el más grande de los bienes y al darse cuenta después de la insondable distancia que lo separa de Él. El melancólico se retraía de su fin divino no porque lo olvidara o dejara de desearlo, sino por-

2 Las 'filiae acediae' o hijas de la acedia que enumera San Gregorio son la 'malitia' (odio-amor por el bien), la 'pusillanimitas' (el retraimiento frente a la dificultad y el empeño de la vida espiritual), el 'torpor' (el somnoliento estupor que paraliza cualquier intento de cura), la 'evagatio mentis' (la fuga del ánimo ante sí mismo y el inquieto discurrir de fantasía en fantasía. Se refiere a la incapacidad para controlar el incesante discurso -co'agitatio' - de los fantasmas interiores).

3 Según E. Rohde, el demonio meridiano se llamaba así porque se lo asociaba a Empusa, uno de los espectros del séquito de la diosa Hécate griega, que aparecía precisamente al mediodía.

4 AQUINO, Tomás de (santo). Suma teológica. Buenos Aires, Ed. Club de Lectores, 1948. II, 2.35. 
que no deseaba la vía que conducía a la salvación, a Dios, vía que lo mostraba claramente inalcanzable. Aun así, el hombre persiste en el deseo de un objeto que él mismo ha hecho inalcanzable para sí, en la contemplación de una meta que se muestra como tal en el mismo acto en que le resulta vedada, y mientras más inalcanzable, más se obsesiona con ella. Hay un fin pero no hay medios y no se puede huir de esta situación paradójica porque no se puede huir de lo que nunca se alcanzó.

Desde una perspectiva cristiana, Kierkeggard (1813-1855) relaciona la angustia con la inocencia, la ignorancia y el pecado; veamos cómo. El ser humano se encuentra en los principios en un estado de inocencia. Este estado, que es inmediato, no tiene la finalidad inmediata de ser anulado. La inocencia no es una nada que comienza a ser sólo cuando se la trasciende. La inocencia existe y es un estado. Ésta se pierde cuando se toma conciencia de ella y eso sucede porque la inocencia es fundamentalmente ignorancia, es desconocimiento de la diferencia entre el bien y el mal. El hombre que ha cometido un pecado pierde la inocencia $y$, sin embargo, esto origina un salto cualitativo en el individuo porque al salir de la inocencia sale de la ignorancia.

Pero la angustia, que es el tema que nos ocupa, no nace de la culpa por un pecado concreto porque eso significaría que el que se angustia lo hace por algo en concreto. La angustia, por el contrario, nace de la inocencia, de la ignorancia respecto a todo, respecto de la diferencia entre el bien y el mal. Se trata de un estado de paz que agita al espíritu. El hombre se angustia ante la nada que se le muestra pero también ante la posibilidad de la libertad, ante la angustiosa posibilidad de "poder". Pone un ejemplo bíblico: Adán sabía que podía, pero no sabía qué era eso que podía, ya que no distinguía bien de mal por encontrarse en la inocencia, en la nada que engendra angustia, en la nada que es "poder" pero no "haber podido".

Dice Kierkegaard que

La angustia es la realidad de la libertad como posibilidad antes de la posibilidad y que, como un poder extraño [que] 
hizo presa en él [el hombre], un poder que él no amaba, del cual, por el contrario, se apartaba angustiado; y sin embargo es culpable: se había hundido en la angustia, a la que amaba a la vez que temía 5 .

En el espíritu del hombre se da así una ambigüedad de la que no se puede liberar: no puede huir de la angustia que ama ni amar la angustia de la que huye. La relación del ser humano con el objeto de angustia es ambigua, justamente porque ese objeto no es algo en concreto; el hombre se angustia de nada. El hombre es algo incomprensible para él mismo.

Lo que angustia al ser humano no es la culpa sino la prohibición, que le despierta la posibilidad de la libertad. En el estado de inocencia lo angustiaba la nada y ahora lo angustia la posibilidad de poder, algo superior a su anterior ignorancia. Y sin embargo, no se acerca a esto superior, más bien huye, porque a la prohibición le sigue el castigo y esta es otra posibilidad.

Según hemos visto hasta ahora, la angustia inquietó al pensar tanto en el ámbito de la teología como en el de la filosofía, y en los próximos párrafos veremos cómo la angustia toma otros alcances con Freud, dentro de la psicología. El lector podrá notar la estrecha relación que alcanzan en Freud la psicología y la filosofía, teniendo como línea divisoria la transgresión a los límites positivistas de la psicología y el intento de dar explicación a aquello que se escapa de lo empírico, de lo observable y comprobable.

Freud (1856-1939) expone su teoría sobre la angustia en Duelo y melancolía. Allí explica que tanto la melancolía como la aflicción ${ }^{6}$, se refieren a la reacción de un sujeto frente a la pérdida o muerte de un

5 KIERKEGAARD, Sören. El concepto de angustia. Bs. As., Ed. Espasa Calpe, 1940. Cap. I, apartado 4.

6 Las investigaciones freudianas tienen como objetivo delimitar la experiencia melancólica, a fin de que se alcance la validez general requerida a todo conocimiento dentro del marco de las ciencias positivas. Este objetivo es alcanzado respecto al tema de la aflicción pero no de la melancolía. 
objeto o de una abstracción equivalente (patria, libertad, etc.). Incluso poseen similares rasgos sintomatológicos, como por ejemplo: estado de ánimo de profundo dolor, desinterés por el mundo exterior, incapacidad para elegir un nuevo objeto de amor y olvidar el anterior, incapacidad para amar a otros, $y$, además, poseen un similar comienzo: un sujeto examina la realidad y nota que el objeto amado no está en ella. Por un lado, la libido le exigirá que abandone dicho objeto y todo lo relacionado a él; por otro, el sujeto se resistirá a abandonar el objeto perdido porque no quiere sustituirlo. Subsiguientemente, el sujeto puede reaccionar de dos modos, a saber, de un modo psicológicamente normal, bajo la aflicción, o de un modo patológico, bajo la melancolía.

En el primer caso, al tomar conciencia de la pérdida, el sujeto irá cediendo, se irá alejando paulatinamente de tal objeto con doloroso displacer y desplazará su libido hacia otro objeto de amor. En el segundo caso, el sujeto desarrolla una predisposición morbosa al no reaccionar conscientemente a la pérdida y, por lo tanto, desconoce qué sea eso que ha perdido, ya sea porque lo perdido está en el inconsciente, ya sea porque lo perdido nunca existió y consiguientemente nunca pudo haberse perdido. En otras palabras, hay una diferencia entre el afligido que es consciente de lo perdido y el melancólico que no lo es y en el que la enfermedad se desarrolla en el inconsciente.

Agamben ${ }^{7}$ considera que en esta situación la melancolía no sería tanto una reacción regresiva ante la pérdida de un objeto de amor, sino la capacidad fantasmática de aparecer como perdido un objeto inapropiable. Se vuelve a considerar aquí la idea de que la voluntad transforma en objeto de abrazo lo que debería haber sido sólo objeto de contemplación. La melancolía se origina en el intento de abrazar ese objeto inapropiable y/o irreal. La percepción de lo real le muestra un conflicto pero su deseo le empuja a negar tal percepción y, así, continúa relacionándose con el objeto anterior, el cual sigue latente y reprimido en el inconsciente.

\footnotetext{
AGAMBEN, Giorgio. Estancias. Valencia, Ed. Pre-textos, 1995.
} 
Concretamente, lo que sucede con el afligido es que reemplaza un objeto de amor por otro, mientras que el melancólico no desplaza su libido hacia otro objeto de amor sino que regresa al estado primitivo, se retrae sobre sí mismo, haciendo que el yo se identifique no con otro objeto, sino consigo mismo, y es esto a lo que Freud denomina narcisismo. En la melancolía es el propio yo quien resulta perdido y en vez de haber una relación "yo-persona amada", hay una relación "crítica del yo - yo modificado por la identidad consigo mismo". Esto sucede porque el melancólico tiene la característica de percibir más claramente la verdad y su autocrítica negativa suele acercarse considerablemente al autoconocimiento: el sujeto se pone frente a sí, se objetiviza para criticarse. Los reproches que se hacían al objeto amado se hacen ahora a sí mismo.

Ricoeur ${ }^{8}$ sostiene que siempre se ha pensado en lo consciente como el contenido seguro y cierto de la psiquis del hombre, pero ésta es una de las lecturas de entre todas las posibles que se pueden hacer de la teoría freudiana. Para él, la consciencia no es la primera certidumbre sino sólo una percepción. Lo fundamental no es el contenido de la consciencia o el contenido reprimido del inconsciente sino las relaciones de los actos psíquicos y las pulsiones. Lo que interesa es saber cómo resuelve el hombre el hecho de que sus pulsiones busquen ser satisfechas, busquen alcanzar su fin, sin que tal satisfacción o logro del fin esté asegurado de antemano por la naturaleza del hombre. Freud trata este tema en su obra Los impulsos y sus destinos.

Freud comienza por distinguir entre estímulos externos e instinto. Respecto de los primeros dice que tales estímulos permiten al hombre satisfacer sus pulsiones por medio de una acción, de un único acto adecuado, que consiste en la fuga motora ante la fuente de la cual emana tal pulsión. Por otro lado, el instinto (o estímulo instintivo), que no procede del exterior sino del interior del organismo, si bien también satisface las pulsiones por medio de la acción, ésta no re-

8 RICOEUR, Paul. Freud: una interpretación de la cultura. México, Ed. Siglo XXI-México, 1999. 
sulta una fuga eficaz porque el instinto es una fuerza constante (no momentánea). El carácter de fundamental de este instinto radica en que es un signo característico del mundo interior del hombre y se encuentra en el límite entre lo anímico y lo somático.

Cualquiera sea el destino de la pulsión ${ }^{9}$, lo que se observa es que el yo tiende a incorporar a sí mismo lo que le representa una fuente de placer y a alejar de sí lo que no lo es, fugándose de la parte del mundo exterior que le resulta hostil y displicente. Esto deja entrever una base narcisista en el hombre, el cual, movido por la propia supervivencia, rompe con todo objeto externo-displicente para identificarse sólo con lo placentero y constituirse él mismo en fin de toda pulsión.

En este escrito, encontramos una nueva orientación freudiana en la cual no interesa ya tanto lo reprimido sino lo represor. De lo represor hay un primer origen que se encuentra en la humanidad, en un hecho social anterior a cada hombre: en figuras históricas constituidas o en un otro que es la autoridad (familia, tradición, costumbre, instrucción, poder político o eclesiástico, sanción penal o social). Luego, lo represor se encuentra también dentro del mismo hombre... pero ¿por qué sucede o con qué finalidad? Sucede que el yo necesita dominar toda situación, necesita dominar los impulsos (Ello) y defenderse de la amenaza que éstos representan para él.

El mayor peligro para el hombre proviene del interior de él mismo entonces, además de librarse de la amenaza por la huida, el yo se libra de ella por la percepción, por la conciencia, que es un filtro, un escudo contra los estímulos externos. En palabras de Freud, el hombre es un ser esencialmente amenazado por dentro; por eso hay que agregar al peligro exterior, la amenaza de los instintos, fuente de angustia, y la amenaza de la consciencia moral, fuente de culpabilidad ${ }^{10}$. La fuerza represora

9 Freud enumera cuatro destinos: la transformación en lo contrario, la orientación contra la propia persona, la represión y la sublimación.

10 Es oportuno recordar que se dijo que la autocrítica del melancólico es el origen de la conciencia moral, según Freud. El hombre que es sí mismo es el que domina sus actos y este hombre se diferencia completamente del 
es llevada a cabo por el superyó, que se sirve de la consciencia como recurso o medio para lograr su fin. Ese superyó actúa de tres modos: por la observación, la consciencia moral y el ideal ${ }^{11}$. La acción del superyó sobre el yo hace extraño al yo su sí mismo.

Freud encuentra en Edipo el ejemplo perfecto para explicar que la cultura nace de la represión del deseo, del instinto. En la libido están latentes todas las infracciones a la moralidad común. Por lo tanto, se ve claramente que el ingreso a la cultura le supone al hombre un conflicto y conlleva cierto grado de sufrimiento. En otras palabras, la civilización se edifica a expensas de las pulsiones sexuales, de su no utilización por la amenaza de perversión que éstas implican. La cultura, a la sombra de la sublimación, protege al individuo contra la supremacía de la naturaleza, disminuye la carga de sacrificio impuesto a los instintos humanos, hace que los individuos se reconcilien con las renuncias inevitables y ofrece satisfacciones que compensen los sacrificios. Toda transición consiste en una crisis y una renuncia y esa transición a la culturalización que el hombre experimenta es un trabajo de duelo, una crisis profunda y de gran importancia. La elección y/o abandono de objetos no es algo fortuito sino que implica un duro aprendizaje.

Una de las vías de formación del superyó es la idealización, junto con el narcisismo que ésta lleva aparejado: el yo se identifica con un yo ideal que se formó para sí mediante la fuerza represora de los padres, es decir, la autoridad. En este marco se originan la melancolía y la regresión que ésta implica (giro narcisista), como preámbulo necesario

hombre moral o ético al que la obligación lo hace débil. [El lector encontrará las similitudes pertinentes de estas últimas palabras con el pensamiento de Nietzsche]

11 Funciones del superyó: observación (desdoblamiento que se experimenta como ser observado, vigilado, criticado, condenado), conciencia moral (supone la observación cruel que se opone a la acción o que reprueba después de la acción; así, el yo se siente mirado y también maltratado por su otro interior y superior) e ideal (el superyó representa el ideal para el yo y el yo intenta conformarse al ideal, intenta parecérsele, intenta perfeccionarse obedeciendo siempre sumiso a sus demandas). 
para la sublimación. La sublimación no reprime las pulsiones sino que las convierte. Esto significa que satisface las exigencias del yo sin ocasionar represión. Esto sucede así porque, en la sublimación, el fin de las pulsiones ya no tiene que ver con un objeto particular $y$, además, porque el fin siempre es el mismo.

En el punto crucial del psicoanálisis, Freud constata que el hombre está constantemente experimentando dos fuerzas opuestas que le son intrínsecas: la que proviene del yo, relacionada con el instinto, y la que proviene del superyó, relacionada con el trabajo de la cultura. Por un lado, la tendencia del yo a apropiarse sólo de lo que representa para él una fuente de placer y, por el otro, el superyó que, actuando como fuerza represora, le exige seguir las pautas que delimita la cultura (autoridad) y apartarse de la amenaza que representan los instintos.

Con lo dicho hasta aquí, podemos ver que en Freud se hallan dos elementos que ya nos son familiares: la huida del yo ante lo amenazante, que en el lenguaje freudiano es el impulso (lo que constituye originariamente al hombre o lo "primitivo" en él), y la ambigüedad de un hombre que, queriendo para sí sólo lo placentero, se encuentra con una prohibición (impuesta por la cultura) que le cierra el camino y que lo obliga a regresar a sí mismo (narcisismo). Aquí es donde se enmarca la melancolía que ya hemos caracterizado.

Heidegger (1889-1976) hace un aporte importante al tema que nos ocupa. Podríamos decir que su aporte es el más filosófico ya que hay un distanciamiento de elementos teológicos y psicológicos. La angustia es parte fundamental de la analítica existenciaria y veremos de qué modo, primero comenzando por ¿Qué es metafísica? (1929).

Con el imperio moderno de la razón sobre todo lo demás, la filosofía sufrió un golpe del cual le fue difícil recuperarse. Quedaron sentadas las bases de un conocimiento legítimo y válido: el conocimiento científico fundamentado en el dato empírico, en el ente mismo, que por rigor y exactitud dejan en menos cualquier otro tipo de conocimiento, como es el de las ciencias del espíritu. El problema es que la 
ciencia no se hace sola e irrumpe en su hacer otro ente del mundo que es el hombre, un ente del mundo que antes de hablarnos de un ente fuera de él, nos habla de él mismo como ente capaz de referir a algo. El referirse del hombre le permite a éste recuperarse a sí mismo y el dato empírico deja de tener la última palabra, así como también las Ilamadas ciencias exactas. Este hombre puede preguntarse por los entes pero también se pregunta, en una clara actitud filosófica o metafísica, por lo que está más allá de ellos, plano insignificante para la ciencia, algo que para la ciencia no era nada. Para la ciencia, lo que hay que inquirir es tan sólo el ente y, por lo demás, nada; el ente sólo y nada más; únicamente el ente y fuera de él, nada ${ }^{12}$.

La nada es lo que la ciencia rechaza y abandona por ser nadería, dice Heidegger. Sin embargo, al abandonar la nada la ciencia la está admitiendo y la filosofía es quien se pregunta por ella. Se produce una situación paradójica: sobre la nada no se puede ni preguntar ni responder sin incurrir en un contrasentido. Si se responde qué es la nada, se afirma que ella es algo y si se pregunta qué es ella, nuestro pensamiento eminentemente lógico que siempre es pensar de algo, se encontraría pensando en torno a la nada e iría en contra de su propia esencia; no obstante lo hace y eso nos lleva a concluir que la negación es también un acto del entendimiento.

Ahora bien, el preguntarse por la nada supone una búsqueda de nuestra parte; pero ¿cómo podría uno querer encontrar lo que no sabe que está allí porque es no es nada? Para poder predisponernos a la búsqueda de la nada se necesita de un estado de ánimo completamente distinto a otros, justamente porque esos otros estados están referidos a lo que es, a lo ente, y nos ocultan, en todo caso, la nada. El temple que se necesita es el de la angustia.

Es verdad que la angustia es siempre angustia de..., pero no de tal o cual cosa. La angustia de... es siempre angus-

12 Heidegger, Martin. Qué es metafísica. Buenos Aires, Ed. Siglo XX, 1970. Planteamiento de un interrogante metafísico. Pág. 2. 
tia por..., pero no por esto o lo otro. Sin embargo, esta indeterminación de aquello de lo que... y por qué nos angustiamos, no es una mera ausencia de determinación, sino la imposibilidad esencial de ser determinado ${ }^{13}$.

Hasta aquí, Qué es metafísica nos explica cuál es el estado de ánimo originario que mueve al ser ahí a preguntarse por la nada. Sin embargo, esta nada no se encuentra separada del todo del ente $y$, por el contrario, está a una con el ente en su totalidad. Lo que sucede es que en

La angustia el ente en total se torna caduco. ¿En qué sentido?

Porque la angustia no aniquila el ente para dejarnos como residuo la nada. ¿Cómo habría de hacerlo si la angustia se encuentra precisamente en la más absoluta impotencia frente al ente en total? Antes bien, la nada se manifiesta con $y$ en el ente en tanto que éste se nos escapa en total ${ }^{14}$.

Es por este motivo que la angustia se halla relacionada, en principio, con la caída y con el encontrarse ${ }^{15}$, como podemos ver en Ser y tiempo. El ser ahí cae en el Uno, en el "mundo" del que se ocupa (del que se cura) y es absorbido perdiéndose y cayendo en el público estado de interpretado, es decir, dejando que sea lo Uno quien dé significado y abandonando su ser sí mismo, su posibilidad más propia de ser. Respecto a este punto, es necesario decir que

El estar perdido en el Uno, que caracteriza al Dasein como "impropio", no se refiere a la impropiedad sobre el fondo de una "propiedad" genuina al modo de un "no-estar-

\footnotetext{
13 Ídem, pág. 3.

14 Ídem, pág. 4.

15 (cf. parágrafo 29) El encontrarse es lo más conocido ónticamente, a saber, el temple o el estado anímico. El ser ahí está siempre afectivamente abierto como el ente que tiene que ser existiendo. En el encontrarse el ser ahí está puesto ante sí mismo; el ser ahí se encuentra encontrándose; el ser ahí encuentra que desde siempre ha debido encontrarse. Sin embargo, no se ha encontrado encontrándose como fruto del buscarse, sino al contrario, del fugarse.
} 
ya-en-el-mundo", sino que designa un estado positivo de este ente y constituye el modo eminente y privilegiado de "estar-en-el-mundo". Este "no-ser" no es una mera negación, sino la forma fáctica y el modo de ser inmediato del Dasein $^{16}$.

En otras palabras, este modo impropio del ser ahí de estar en el mundo en estado de cerrado no es algo negativo, sino todo lo contrario: es su modo inmediato de ser, en el que él se mueve ordinariamente, es un momento necesario en el que la angustia le hará patente su estar vuelto hacia el más propio poder ser, le revela su libertad para escogerse y tomarse a sí mismo entre manos. Y esto porque el ser ahí es, desde siempre, la posibilidad de ser él mismo y aquí radica la propiedad de su ser. Reitero que el "estar-en-el-mundo" no significa enajenación (por eso la alienación heideggeriana es distinta a la que postuló el marxismo, por ejemplo), corrupción, degeneración sino que es un modo de habitar la cotidianidad, un modo propio y auténtico.

La angustia propia es el camino por excelencia para llegar al estado de abierto que aísla, que saca al ser ahí de su caída y le revela la propiedad e impropiedad tal como son, es decir, como posibilidades de su ser. La caída es un modo del ser ahí de estar en el mundo y, por lo tanto, no es un fenómeno que se pueda evitar sino uno que constituye esencialmente al ser ahí. La alienación ${ }^{17}$ en la cual se precipita el ser ahí lo sustrae a éste de sus posibilidades y le oculta su poder ser más propio. Es decir que el Uno aliena al ser ahí en su ser y le oculta las posibilidades de desplegarse en cuanto tal tras el efecto tranquilizador ${ }^{18}$ producido por la cotidianidad. Alienación y caída actúan juntas, bajo la forma de "progreso" o "vida real", mostrando al ser ahí una estabilidad imaginaria en la que, en realidad,

\footnotetext{
16 ALBANO, S. y NAUGHTON, V. Lacan: Heidegger. Nudos de Ser y tiempo. Bs. As., Ed. Quadrata, 2005. Pág. 91.

17 Cf. Parágrafo 38.

18 Tranquilidad que paradójicamente no conduce a la quietud sino a un ajetreo desenfrenado que acrecienta la caída.
} 
han sido previamente ordenadas y dispuestas todas las posibilidades de ser del ser $a h i^{19}$.

Es por la caída que el ser ahíse retrae y se encuentra fugándose ante sí mismo. La fuga es un retroceder ante lo amenazador que es, en cada caso, un ente intramundano. Pero lo que hace que retroceda no es ese ente concreto, sino que retrocede ante lo absolutamente indeterminado, lo que no está "en ninguna parte". Hay que remarcar que "en ninguna parte" no significa ausencia de mundo ${ }^{20}$, en un sentido espacial, sino que significa que los entes intramundanos carecen de importancia, son "insignificantes"21; esa indeterminación del "en ninguna parte" es lo que angustia y no, por el contrario, el desconocer qué ente intramundano amenace. Sólo porque hay un "mundo" con el que el ser ahí está en relación de comprensión es por lo que existe la posibilidad de angustiarse ante una "nada", ante la pérdida de significado de lo "algo". "Ninguna parte" tiene que ver con el modo en el que el ser ahí está en el mundo, a saber, comprendiendo.

Lo dicho hace manifiesto que el ser ahí no huye de los entes intramundanos sino hacia esos entes de los que se ocupa cuando está perdido en el uno. Es en la publicidad del uno que el ser ahíse siente "en su casa" y por eso huye ante la inhospitabilidad (desazón) del "no estar en su casa", ante el estado de abierto del ser en el mundo yecto,

19 ALBANO, S. y NAUGHTON, V. Lacan: Heidegger. Nudos de Ser y tiempo. Bs. As., Ed. Quadrata, 2005.

20 Hay que recordar que el ser ahí es fundamentalmente ser en el mundo; éste es un modo de ser del ser ahí por el cual él está en relación con las cosas, comprendiéndolas, dándoles significado.

21 Cuando aquí se dice que los entes intramundanos pierden sentido no significa que se caiga en la incomprensión, sino que esos entes carecen de importancia para el ser ahí. Aquí Heidegger juega con dos vocablos alemanes: 'bedeuten' (significar, querer decir) y 'Bedeutung' (importancia) [también en español se da esta doble significación en la palabra "significativo", para indicar a la misma vez que algo tiene significado o que algo es importante]. Lo que pierde importancia no es una cosa u otra, sino el todo de las relaciones significativas, el sentido de las cosas como útiles (que había quedado en primer plano en la vida cotidiana, en el "mundo"). 
ante lo inhóspito del "estar en el mundo" arrojado y entregado a sí mismo en su ser. La angustia arroja al ser ahí contra aquello por lo que se angustia que es su posibilidad de ser en el mundo, de ser sí mismo propiamente, de instalarse en el mundo comprensivamente. Esta fuga hace patente que la posibilidad más propia del ser ahí es la de ponerse ante sí mismo.

Heidegger señala una diferencia entre miedo y angustia. La caída del ser ahí en el Uno y en el "mundo" de la ocupación ha sido explicada como una fuga del ser ahí ante sí mismo. Es entonces cuando el ser ahí se angustia. El miedo, por otro lado, es un encontrarse y, si bien implica un retroceder, éste no es fuga porque en el miedo el ser ahí no retrocede ante un ente de la misma índole del ente que retrocede, es decir ante sí mismo, sino ante un ente intramundano amenazante y perjudicial. En otras palabras, el ser ahí angustiado no retrocede por miedo a un ente intramundano, porque precisamente él se vuelve hacia el ente intramundano y se absorbe en él. El miedo es una angustia caída en el mundo, es una angustia impropia que se oculta para sí misma. El miedo cambia la indeterminabilidad del "ante que" de la angustia en un miedo "por".

La angustia lleva al ser ahí ante la propia nada y la totalidad de lo ente se hace indiferente; ya no hay palabras para referirse a ello. No se trata de que el ser ahí aniquile todo para que quede la nada, sino que, por el contrario, la angustia se manifiesta con lo ente y en lo ente. Se da la paradójica situación de un ir hacia los entes y a la vez, remitir a ellos rechazándolos, retrocediendo ante ellos. En la cotidianidad el ser ahí se pierde por completo en lo ente y la angustia queda oculta; pero, sólo entonces, al ser ahí se le revelará su finitud más propia.

¿Cómo llega a angustiarse el ser ahî? La angustia originaria reprimida en el ser ahí está adormecida en la cotidianidad y puede despertar en cualquier momento, sin necesidad de un acontecimiento extraordinario o de algún artilugio humano que le traslade a ella. El ser ahí no se puede angustiar por decisión o voluntad propias. Lo único que se puede afirmar con seguridad es que primero es necesario que el ser 
ahíse pierda en lo ente en su totalidad para luego poder abandonarse a la nada y liberarse de su cotidiana y habitual evasión. Así es como emergerá de lo oculto la pregunta por el sentido del ser.

\section{Conclusiones}

La intención de este trabajo es rescatar la angustia una vez más del olvido, tratando de llegar a la fibra profunda que recorre el pensar occidental y que ha sido encubierta por la cotidianidad. Todo el mundo lo usa constantemente [el concepto de "ser"] y comprende ya siempre lo que con él quiere decir. De esta manera, lo que estando oculto incitaba y mantenía en la inquietud al filosofar antiguo, se ha convertido en algo obvio. Por el contrario, en este trabajo nos hemos saltado la obviedad que pasa por alto y olvida y, también, hemos trascendido la comprensión mediana (o de término medio) ${ }^{22}$ que tenemos de la angustia, porque si bien dicha comprensión permite que la angustia no nos sea algo completamente desconocido, sin embargo, hace que la angustia sea algo velado en su originariedad.

Hoy somos herederos de un error de interpretación que consideraba la angustia como un pecado y un mal del cual había que liberarse para alcanzar la salvación... tendemos a pensar la angustia como algo negativo. La asociamos a una tristeza de la que el hombre tiene que liberarse por ser una carga insoportable para su vida. Sin embargo, ya desde la patrística se nos mostró que la 'tristitia' del melancólico que

22 El ser ahí no puede prescindir de la comprensión mediana porque ella es en la que él se mueve desde siempre y que pertenece a su constitución esencial. Sin esta comprensión preontológica o existentiva (existencial) no habrá una comprensión existencial (existenciaria) que pregunte por el sentido del ser. La propiedad (su modo propio de ser en la angustia y su modo propio de comprender existenciariamente) del ser ahí no es algo que este tenga como un agregado del cual pueda prescindir. Por el contrario, él es cada vez esencialmente su posibilidad, él puede elegirse y ganarse a sí mismo cada vez o puede perderse y no ganarse jamás. Pero hay que notar que no puede perderse lo que no se tenía; por lo tanto, el ser ahí siempre se tuvo a sí mismo, como posibilidad, y siempre se ha comprendido a sí mismo de alguna manera, en un término medio (medianidad). 
caía en la cuenta de que el objeto que deseaba le era inalcanzable no era exclusivamente una 'tristitia mortifera' sino también una 'tristitia salutifera' para la cual el objeto deseado y, en principio inalcanzable, no era tal cosa, ya que sólo se puede estar privado de aquello que se ha poseído en mayor o menor medida. Justamente esa ambigüedad, evidente en el Medioevo, es una de las características constitutivas de la angustia: Dios, el más grande de los bienes, como objeto de deseo, la imposibilidad de alcanzarlo que lo hacen retroceder $y$, a la misma vez, amarlo aún más.

Según Kierkegaard la angustia tiene que ver con la ambigüedad del hombre libre, el cual tiene la posibilidad de elegir lo que en él hay de eterno o no, pero hallándose sumergido en la inocencia de saber que puede y no saber qué es eso que puede. El hombre se encuentra angustiado por la posibilidad de poder y por eso intenta huir de ello, pero sin éxito, porque sigue amando aquello que teme.

Freud también da cuenta de la ambigüedad de un sujeto al que la realidad le muestra que no podrá tener su objeto deseado, pero que él insiste en desear. El melancólico rechaza el dato de la realidad que le muestra que el objeto amado ya no está más allí y rechaza también a su libido que le invita a elegir otro objeto de amor; en cambio, persiste en amar el objeto perdido que no se halla más que en sí mismo. Es por esto que el sujeto se retrae sobre sí mismo (giro narcisista) y busca identificarse no ya con otro objeto, sino consigo mismo. Según Freud el hombre es arena sobre la que combaten los impulsos y sus destinos: el sujeto freudiano está angustiado por la ambigüedad que experimenta al querer satisfacer sus instintos $y$, a la vez, tener que obedecer a su yo que atiende órdenes del superyó. El yo queda sepultado bajo esta presión y represión, se hace completamente extraño a sí mismo.

La causa de la angustia está relacionada con algo que va más allá de las cosas del mundo, lo ente. En Kierkeggard, el inocente no se angustia por algo determinado, por una prohibición determinada, sino por la nada que es "poder" pero no "haber podido", por la sola posibilidad de poder. En Freud, el melancólico se ve privado del objeto 
que desea, el cual no siempre es algo o alguien determinado, sino que muchas veces va más allá, incluso puede que nunca se lo haya poseído en verdad. Según Heidegger, se trata de un ser que se angustia por la nada, lo indeterminado, por algo no concreto que trasciende lo mundano, por la nada de lo que no está "en ninguna parte", por la insignificancia de los entes intramundanos.

El ser ahíheideggeriano atraviesa una constante ambigüedad al encontrarse en la tranquilidad de la cotidianidad y salir a la inhospitabilidad del "no estar en su casa", estando en el estado de interpretado del uno sale hacia la insignificatividad de la nada. El ser ahíse retrae ante sí mismo y se encuentra a sí mismo fugándose ante sí mismo. El ser ahí se fuga o huye no de los entes intramundanos sino hacia ellos, y esto porque la amenaza no proviene del exterior, de algo concreto, sino que se siente amenazado por lo absolutamente indeterminado, lo que no está "en ninguna parte".

Así como el ser se ha convertido desde Platón y Aristóteles en una trivialidad $^{23}$, así como la pregunta por el sentido del ser ha sido declarada superflua, así también se ha olvidado la significativa importancia de la angustia. No han sido frecuentes los intentos por interpretar el fenómeno de la angustia en su fundamental constitución y su función ontológico-existenciaria y esta omisión se enmarca en una aún mayor que es la que ha olvidado emprender una analítica existenciaria del ser ahí. Sin embargo,

La infrecuencia del fenómeno [de la angustia] es un índice de que el Dasein, pese a quedar habitualmente oculto a sí mismo en su carácter propio, en virtud del estado interpretativo público del uno, puede, sin embargo, ser abierto en forma originaria en esta disposición afectiva fundamental ${ }^{24}$.

23 HEIDEGGER, Martin. Ser y tiempo. Santiago de Chile, Ed. Universitaria, 1998. Parágrafo 1.

24 Ídem, Parágrafo 40, pág. 212 (pág. 190 del original alemán). 
Este trabajo nos ha permitido abrir el espectro de esos intentos infrecuentes por interpretar el fenómeno de la angustia, nos ha ido guiando para que comprendamos la importancia de la angustia como modo propio de ser sí mismo y nos ha acercado a la experiencia misma de la angustia; siempre con la intención de que al volver sobre ella la desocultemos del encubrimiento que la ha olvidado.

\section{Bibliografía}

AGAMBEN, Giorgio. Estancias. Valencia, Ed. Pre-textos, 1995.

ALBANO, S. y NAUGHTON, V. Lacan: Heidegger. Nudos de Ser y tiempo. Bs. As., Ed. Quadrata, 2005.

AQUINO, Tomás de (santo). Suma teológica. Buenos Aires, Ed. Club de Lectores, 1948. II, 2.35.

DI SILVESTRE, Carlos. El concepto metódico de repetición en la hermenéutica de Martin Heidegger. Mendoza, Revista Philosophia de la Facultad de Filosofía y Letras de la Universidad Nacional de Cuyo, 2004. Páginas 36-61.

FREUD, Sigmund. Obras completas. Madrid, Ed. Biblioteca Nueva, 1967.

HEIDEGGER, Martin. Ser y tiempo. Santiago de Chile, Ed. Universitaria, 1998.

HEIDEGGER, Martin. ¿Qué es metafísica? Buenos Aires, Ed. Siglo XX, 1970.

JOLIVET, Régis. Las doctrinas existencialistas desde Kierkegaard a J. P. Sartre. Madrid, Ed. Gredos, 1950.

KIERKEGAARD, Sören. El concepto de angustia. Buenos Aires, Ed. Espasa Calpe, 1940.

RICOEUR, Paul. Freud: una interpretación de la cultura. México, Ed. Siglo XXI, 1970. 